\title{
LA SUCESION DE SUSPENSIONES DE LICENCIAS EN LA JURISPRUDENCIA RECIENTE
}

\author{
POR \\ Antonio Domínguez Vila
}

La técnica de la suspensión de licencias, como medida preparatoria cautelar, al momento de proceder a estudiar o tramitar el planeamiento urbanístico, tiene la virtualidad fundamental de que el objetivo querido por el legislador es la evitación de que se produzcan y consoliden situaciones al amparo de un planeamiento ya caduco o agotado, que va a ser sustituido por otro, y hagan inviable la aplicación del nuevo, tanto por la buena fe de los instantes, o por desaprensivos, que al tener conocimiento que los nuevos criterios ordenadores disminuyen o recortan sus expectativas urbanísticas se apresuran a precipitar su consolidación solicitando las licencias oportunas.

La regulación legal de esta técnica cautelar se encuentra en la habilitación legal general del artículo 72 de la Ley de Procedimiento Administrativo por el que, en previsión de la pérdida de eficacia de una resolución en un procedimiento administrativo, y la aprobación de un plan urbanístico lo es, se podrán adoptar las medidas provisionales que se estimen oportunas, con el límite de no causar perjuicios irreparables a los interesados o violar derechos amparados en las Leyes.

El artículo 27 del Texto Refundido de la Ley del Suelo concreta el régimen de la suspensión de licencias en el ámbito urbanístico, desarrollado por los artículos 117, 118 y 122 del Reglamento de Planeamiento Urbanístico y 104 y 105 del de Gestión Urbanística, modificados sustancialmente por el artículo 8 del Real Decreto-ley $16 / 1981$, de 16 de octubre. Sobre el régimen anterior, los problemas interpretativos planteados y la relación entre las dos variedades de suspensión, es mejor remitirse a la doctrina producida al respecto (1).

(1) Vid. por todos:

Arozamena Sierra, J.: «Suspensión del otorgamiento de licencias. Eficacia del acuerdo de suspensión: queda subordinada a la publicación. Licencia denegada antes de la publicación: es improcedente la denegación. Solicitudes con derecho a indemnización», en $R D U$, núm. 48, 1976, páginas 139-141.

Arozamena Sierra, J.: «Suspensión del otorgamiento de licencias. Prórroga de la suspensión. Requisitos. Acuerdo de suspensión con excepciones indeterminadas», en $R D U$, núm. 59, 1978, páginas 151-156.

Boquera Oliver, J. M.: «La suspensión del otorgamiento de licencias con el fin de estudiar Planes de ordenación urbanas, en $R D U$, núm. 11, 1969, pp. 13-34.

Castro Troncoso, J. L.: «La suspensión del otorgamiento de licencias en el nuevo artículo 22 de la Ley de Reforma (de la de 12 de mayo de 1956, sobre Régimen del Suelo y Ordenación Urbana)», en $R D U$, núm. 45, 1975, pp. 61-76. 
La nueva regulación del Real Decreto-ley citado, aunque innovativa, se basa en los mismos principios de la anterior:

- Suspensión facultativa y automática.

- Prohibición de efectuar nuevas suspensiones en un plazo de cinco años, cuando concurran las siguientes circunstancias: idéntica naturaleza del instrumento de planeamiento, idéntico objeto del planeamiento y distinta finalidad del mismo.

El régimen de relación o articulación de ambas suspensiones (facultativa y automática) se concreta en:

- Se mantiene la independencia entre ambas posibilidades.

- La posible acumulación entre las mismas cede ante el límite general de dos años en que, como máximo, se podrá mantener por cualquiera de las vías.

Por ello, caben -siguiendo a PAREjo Alfonso- tres hipótesis posibles:

1. Se acuerda la suspensión facultativa y se produce la aprobación inicial dentro del período de vigencia de la misma (un año). En este caso opera el apartado 3 del artículo 8 del Real Decreto-ley por el que la suspensión facultativa se extiende a un plazo, como máximo, de dos años, desde la fecha del primer acuerdo, pero sólo en aquellas áreas o zonas «cuyas nuevas determinaciones de planeamiento supongan modificación de la ordenación urbanística» y sus efectos se extinguen, en todo caso, transcurridos los dos años antes referenciados.

2. Cuando no se produce el acuerdo de aprobación inicial dentro del período de vigencia de la suspensión facultativa, éste decae, siendo imposible acordar nuevas suspensiones en el plazo de cinco años por idéntica finalidad.

Castro Troncoso, J. L.: «La suspensión del otorgamiento de licencias en el Reglamento de Planeamiento», en $R D U$, núm. 62, 1979, pp. 55-72.

Fortes ENGELS, J. M.: «La suspensión del otorgamiento de licencias como limitación temporal del ius aedificandin, en el volumen colectivo La vinculación de la propiedad privada por planes y actos administrativos, Madrid 1977, pp. 321-333.

LARIOS TABUeNCA, F.: «Los actos preparatorios del planeamiento y la iniciativa particulan, en $R D U$, núm. 59,1978 , pp. 33-67.

Martín Blanco, J.: «Dictamen sobre procedencia de la denegación de licencia para construir acordada por el Ayuntamiento de $\mathrm{X}$ en virtud del acuerdo previamente adoptado de suspensión en el otorgamiento de licencias al amparo del artículo 22 de la Ley del Suelo; e interpretación del contenido, requisitos y efectos del mencionado precepto legabs, en el vol. Dictámenes y estudios en Derecho urbanistico, ed. Montecorvo, Madrid 1970, pp. 287-313.

Martinez Lafuente, A.: «Prórroga de la suspensión del otorgamiento de licencias de parcelación y edificación con el fin de estudiar el Plan de Ordenación o su reformas, en $A D G C E$ (66-73), I, 1975, pp. 553-558.

Asi como García de Enterria-Parejo, L.: «Lecciones de Derecho Urbanístico», en Civitas, 1981, y Parejo Alfonso, L.: Instituciones de Derecho Urbanistico, edc. Ciudad Argentina, 1986. 
3. Cuando sólo se produce la suspensión automática al acordarse la aprobación inicial, sin haberse adoptado la facultativa, ésta puede alcanzar el plazo máximo de dos años.

En todo caso, cualquier tipo de suspensión se extingue con la aprobación definitiva del instrumento de planeamiento de que se trate.

El artículo 122 del Reglamento de Planeamiento Urbanístico estableció que la interpretación del término idéntica finalidad radica en la diferente naturaleza del planeamiento que justifique ambas iniciativas cautelares. Entendiéndose por la doctrina que el precepto reglamentario se excedió en el desarrollo del artículo 27 de la Ley del Suelo y, por lo tanto, procedia declarar su nulidad. PAREJo interpreta que este artículo, yendo un poco más allá aún que la norma reglamentaria, en el sentido de que no sólo es preciso, ante una nueva suspensión facultativa, la mera invocación de la distinta naturaleza del nuevo instrumento de planeamiento a redactar, sino basar en razones sustantivas la diversa naturaleza real de las dos iniciativas, que en ningún caso deberá confundirse con la distinta naturaleza de ordenación del sistema de planes que nuestra legislación establece entre planes de ordenación integral del territorio y planes de ordenación sectorial, distinción que se mueve en el plano de las diversas funciones de ordenación global o sectorial atribuidas a cada uno de ellos.

Esta avanzada interpretación ha sido confirmada por la jurisprudencia del Tribunal Supremo que se va a analizar a continuación.

El sentido teleológico de la suspensión de licencias es evitar que surjan actuaciones urbanisticas obstaculizadoras de las nuevas previsiones del plan (Sentencia del Tribunal Supremo de 10 de abril de 1978, Arz. 1578, de 3 de octubre de 1980, Arz. 3831 y sentencia del Tribunal Supremo de 17 de octubre de 1983, Arz. 5843), por lo que se hace prevalecer el interés público sobre el privado, prevalece el interés público superior de la programación del desarrollo urbano sobre el privado de la ordenación urbanística, o como magistralmente expresa la Sentencia del Tribunal Supremo de 22 de julio de 1983 (Arz. 4089), al definir el concepto de planeamiento y la misión de las medidas cautelares, cuya cita se hace precisa:

«... proclama el claro y trascendente principio de que el urbanismo, como función pública, exige una acción planificada, afirmando que el planeamiento es la base necesaria y fundamental de toda ordenación urbana, y ello, a nivel estrictamente municipal, a través de la redacción y aprobación definitiva de los Planes Generales, Planes Parciales y Especiales, Estudios de Detalle y proyectos de urbanización, 
públicos, ejecutivos y obligatorios, no sólo para los administrados, sino también para la Administración -Sentencias de 10 de junio de 1966, 2 de febrero de 1968 (R. 1610), 9 de mayo y 22 de diciembre de 1970 (R. 5555), 18 de enero de 1973 (R. 350), 21 de noviembre de 1974 (R. 4995), 17 de abril y 14 de noviembre de 1975 (R. 2557 y 4910$), 23$ de enero y 2 de febrero de 1976 (R. 640 y 751) y 6 de junio y 3 de diciembre de 1979 (R. 2683 y 4349)-; el planeamiento urbano supone anticipar y prever el futuro de la ciudad, programarlo en forma imperativa, limitando -en lo necesario- los derechos de los administrados, fundamentales, el de propiedad, ya que, como enseña la Sentencia de la Sala Cuarta de 21 de noviembre de 1969 (R. 5059), el planeamiento urbano es un gradual y coordinado sistema normativo, al que debe ajustarse el ejercicio de las facultades dominicales, constituyendo, por tanto, una modalidad general de la intervención administrativa; de esta forma, el sistema, recientemente innovado, abandona el rígido e inflexible, establecido en la Ley de 1956, para acudir a un sistema de planeamiento urbanístico, dinámico y coordinador, como es la vida misma de la ciudad y de los núcleos urbanos; y si bien es cierto que las facultades suspensivas del derogado artículo 22 de la Ley de 12 de mayo de 1956 (actual art. 27 del Texto Refundido de 9 de abril de 1976), deben ser objeto de una interpretación restrictiva por afectar esencialmente a una de las facultades que integran el contenido normal del derecho de propiedad-Sentencias de 17 de junio de 1963 (R. 3262), 2 de marzo y 15 de noviembre de 1971 (R. 1190 y 4416), 7 de marzo de 1972 (R. 2064), 6 de junio de 1975 (R. 3329) y 16 de junio de 1977 (R. 3370), entre otras-, también es cierto que sin el ejercicio de dichas facultades por los Ayuntamientos se impediría o, por lo menos, se obstaculizaría todo intento de planeamiento urbanístico, al poder actuar la iniciativa privada, en total o parcial disconformidad con el fin del planificador...»

Dos son las cuestiones principales sobre la articulación de la suspensión facultativa y la automática de licencias que ha tratado la jurisprudencia reciente:

\section{A) Plazo máximo.}

Sobre los plazos máximos de actuación de ambas variedades de suspensiones, conjuntamente o por separado, es interesante citar la Sentencia del Tribunal Supremo de 15 de mayo de 1983 porque, 
aunque aplica el artículo 27 del Texto Refundido de la Ley del Suelo de 9 de abril de 1976, en sus considerandos primero y segundo sienta el criterio del máximo plazo de dos años, que luego se verá refrendado en el artículo 8.3 del Real Decreto-ley 16/1981, de 16 de octubre:

«Considerando que la suspensión de licencias... puede producirse por dos vías distintas, o bien "ex lege", mediante la aprobación inicial del proyecto modificativo, siempre que se cumplan los requisitos que la Ley exige; o bien mediante acuerdo expreso previo a la tramitación del expediente de aprobación del plan.

Considerando que, en ambos casos, por precepto expreso se impone una limitación temporal, consistente en un plazo máximo de dos años, cuya expiración, si no hubiere recaido entretanto la aprobación definitiva, determina la imposibilidad legal de que, antes de transcurrir otros cinco años, pueda producirse otra nueva suspensión, sea legal o expresa, que se refiera a la misma zona y por idéntico motivo.»

En idéntico sentido del plazo máximo se pronuncia la Sentencia del Tribunal Supremo de 12 de abril de 1985 (Arz. 2202).

Sin embargo, la Sentencia del Tribunal Supremo de 27 de enero de 1986 (Arz. 2139) exige, sin perjuicio del plazo máximo, la clara determinación o concreción temporal del plazo de suspensión de licencias en el acuerdo de su imposición facultativa, no pudiéndose entender que se trata del plazo máximo cuando se produce esta indeterminación, y deviniendo en nulo dicho acuerdo por restrictivo a los derechos individuales.

\section{B) Idéntico motivo y finalidad.}

Este concepto jurídico indeterminado se concreta en la distinta naturaleza del instrumento de planeamiento empleado como motivo para haber acordado la suspensión facultativa.

La jurisprudencia, en Sentencia del Tribunal Supremo de 11 de junio de 1984, basándose en otra de 16 de junio de 1982 (Arz. 4808), interpreta el concepto juridico indeterminado «idéntica finalidad»:

«... si bien es cierto que la ordenación urbana constituye el genérico o común designio de los planes, la conformidad completa o igualdad, en sustancia o accidentes, que define el concepto de identidad, no se da entre sus diversas clases, cuyos específicos objetivos justifican su regulación como grados sucesivos del planeamiento; interpretación que además es corroborada por el artículo 122 del Reglamento de 23 de 
junio de 1978, en el que se precisa que no existe tal identidad entre Planes, Normas, Programas o Estudios de Detalle de diferente naturaleza que la del que originó la primera suspensión.»

Es decir, la idéntica finalidad implica conformidad completa o igualdad entre dos motivos que justifican ambas iniciativas, que puede producirse tanto en el contenido de los planes a estudiar o formular, como en su forma.

También la Sentencia del Tribunal Supremo de 11 de diciembre de 1984, en su considerando segundo, establece que:

«No se entenderá como idéntica finalidad la redacción de un Plan, Normas, Programas o Estudios de Detalle, o su revisión o modificación, con distinta naturaleza que el que motivó la primera suspensión.»

En este caso se suspende en primer lugar para la redacción de un Plan Especial de Equipamientos y en segundo para un proyecto de modificación del Plan General, concluyendo el Alto Tribunal que al ser planes de distinta naturaleza, no existe idéntica finalidad en ambas suspensiones, que es lo vedado por la norma.

En este mismo sentido, la Sentencia del Tribunal Supremo de 19 de julio de 1985 (Arz. 5694) establece que no existe idéntica finalidad por ser de distinta naturaleza juridica, entre un Plan General y un Plan Especial de Reforma Interior.

Sin embargo, la Sentencia del Tribunal Supremo de 30 de septiembre de 1986 se plantea que no excluye la «idéntica finalidad» el hecho de que las figuras de Planeamiento por las que se pretenden dos suspensiones sean de naturaleza distinta, sino que se ha de probar en cada caso, al tratarse de un concepto juridico indeterminado, la inexistencia de una "relación sustancial» (sic) entre ambos instrumentos, ya que en caso que uno sea mero desarrollo de otro sí ha de entenderse que existe idéntica finalidad -en el caso estudiado en la Sentencia entre un Plan General y un Plan Especial de Reforma Interior- debe aquí entrar la determinación sucesiva del concepto jurídico indeterminado por el objeto de la medida, cuando no exista conexión evidente de desarrollo entre ambos Planes, no se vulnera la norma. Hace hincapié, también la doctrina jurisprudencial, en que la prohibición de volver a suspender por idéntico motivo ha de ser siempre referido a las suspensiones facultativas, como más tarde ratificará el Real Decreto-ley 16/1981, citado por la Sentencia.

La técnica de las suspensiones también puede usarse como instrumento de gestión urbanística correlativa a la formulación del nuevo planeamiento. 
El nacimiento de un nuevo Plan General supone un proceso de dificil articulación para la Administración, en el que han de cambiarse muy diversos factores, como el proyecto del grupo político en el Gobierno municipal con los estudios previos del territorio, crecimiento demográfico, dinámica socioeconómica, etc., y sobre todo que la actividad promotora y constructiva no puede ni debe paralizarse, aunque lo intentase la Administración. Ante ello, la experiencia de trabajo con equipos redactores de planeamiento enseña que esta medida cautelar puede ser usada de un modo más dinámico, empleándola sólo con carácter puntual en aquellas áreas que van siendo estudiadas y en las que se detecta la mera posibilidad de «llegar tarde», con el planeamiento y ordenación a realizar. No siendo necesario que tal medida se adopte por el plazo máximo previsto por la Ley, sino el previsible para determinar el destino urbanístico a darle a esa zona, propiciando, sin embargo, que los propietarios puedan solicitar también levantamientos puntuales de suspensiones por el mismo procedimiento que para su imposición, es decir, acuerdo plenario del Ayuntamiento, cuando se estime que la utilización del suelo pretendida no va a interferir el planeamiento a redactar. 
REALA-1988, núm. 237. DOMINGUEZ VILA, ANTONIO. LA SUCESION DE SUSPENSIONES DE LI...

REALA-1988, núm. 237. DOMINGUEZ VILA, ANTONIO. LA SUCESION DE SUSPENSIONES DE LI... 